УДК 668.395.7:595.78

\title{
РАЗРАБОТКА МОДИФИЦИРОВАННОГО СОСТАВА ЭНТОМОЛОГИЧЕСКОГО КЛЕЯ
}

\author{
(ㄷ) С. Н. Лакеев ${ }^{1 *}$, И. Ю. Понеделькина ${ }^{2}$, И. О. Майданова ${ }^{3}$
}

\author{
${ }^{I}$ Уфимский государственный нефтяной технический университет \\ Россия, Республика Башкортостан, 450062 г. Уфа, ул. Космонавтов, 1. \\ ${ }^{2}$ Институт нефтехимии и катализа УФИЦ РАН \\ Россия, Республика Башкортостан, 450075 г. Уфа, пр. Октября, 141. \\ ${ }^{3} \mathrm{OОО} \mathrm{«Инноваиионный} \mathrm{иентр} \mathrm{«Химтэк»}$ \\ Россия, Республика Башкортостан, 450105 г. Уфа, ул. Гагарина, 43/1-29.
}

Тел.: +7 (347) 2948853.

*Email:lakeevsn@gmail.com

\begin{abstract}
Энтомологические клеевые композици используют в клеевых ловушках для отлова вредных насекомых. Разработан модифииированный состав энтомологического клея на основе доступного отечественного сырья с улучшенными характеристиками клейкости и предела текучести и пониженной стоимостью. В качестве агентов липкости в композиции использованы полиизобутилен (ПИБ) с молекулярной массой $15 \cdot 10^{3}-50 \cdot 10^{3}$ в количестве от 8.0 до $15 \%$ мас., бутилкаучук в количестве от 4.0 до $7.0 \%$ мас. и дополнительно - канифоль сосновая в количестве до 5\% мас. В состав композичии также входят низкомолекулярный полиэтилен и индустриальное масло. Бутилкаучук является более доступным полимером на рынке, и его стоимость практически в 2 раза ниже, чем у ПИБ. Полученные клеевые композиции являются прозрачными, нетоксичными, имеют высокие эксплуатационные характеристики.
\end{abstract}

Ключевые слова: энтомологический клей, полиизобутилен, бутилкаучук, низкомолекулярный полиэтилен, канифоль сосновая.

\section{Введение}

Одним из экологичных и безопасных методов защиты растений является так называемый биотехнический метод, основанный на использовании клеевых ловушек. За счет невысыхающей клейкой поверхности и использования различных привлекающих средств (феромонов, цвета определенной длины волны, аттрактантов) клеевые ловушки надежно фиксируют насекомых. Феромонные клеевые ловушки позволяют привлекать только чувствительных к ним насекомых, что дает возможность провести их мониторинг и существенно сократить расход инсектицидов. С помощью цветовых ловушек успешно борются, например, с оранжерейной белокрылкой в тепличных хозяйствах. Клеевые ловушки в виде ловчих поясов, наносимых на ствол дерева, препятствуют миграции насекомых вверх по стволу.

Во всех клеевых ловушках используют невысыхающие жидкие полимерные клеевые композиции, получившие название энтомологических. К энтомологическим клеевым составам предъявляются определенные требования. Они должны обладать хорошей липкостью или фиксирующей способностью, подходящей вязкостью, биосовместимостью, быть нетоксичными, иметь стабильность свойств во времени и необходимый предел текучести или адгезии к рабочей поверхности [1]. Важным фактором является также доступность сырья.

Энтомологические составы являются многокомпонентными и содержат, как правило, агенты липкости (природные или синтетические низкомолекулярные полимеры), структурообразующие до- бавки, создающие пространственную сетку и регулирующие подвижность полимерного компонента, а также вспомогательные вещества и разбавители (масла и др.) для регулирования вязкости.

Разработка отечественных энтомологических клеев проводилась в Уфимском научном центре РАН в 1980-1990 гг. под руководством Ю. А. Сангалова [1-12]. В качестве агента липкости был выбран низкомолекулярный полиизобутилен (ПИБ) с учетом его токсикологических свойств, химической и атмосферной стойкости. Оптимальными структурирующими агентами для ПИБ оказались природные воска и низкомолекулярный полиэтилен (НМПЭ) благодаря их хорошей совместимости с ПИБ. Был разработан базовый состав энтомологического клея под наименованием «Липофикс», включающий, \% мас.: октол-600 или октол-1000 (низкомолекулярный ПИБ) (0.1-20.0); ПИБ с молекулярной массой $15 \cdot 10^{3}-30 \cdot 10^{3}$ (15-33.3); масло индустриальное (25.0-41.1); НМПЭ (16.7-40.0) [2-3]. Разработанная композиция обеспечивала оптимальное сочетание структурной вязкости и поверхностной липкости клея, а также срока эффективного действия из-за придания ему нетекучести с поверхности ловушек. Были предложены также модификации клея «Липофикс» с различными дополнительными компонентами, придающими бактерицидные свойства, увеличивающими липкость и предел текучести [4-12]. Все они прошли успешные испытания в полевых условиях. Отечественными учеными предлагались также составы энтомологических клеев на основе канифоли и ее модифицированных некристаллизующихся производных с добавлением синтетического каучука [13] и с добавлением цере- 
зина и индустриального и растительного масел [14], однако из-за сложного многокомпонентного состава и невысоких эксплуатационных свойств эти варианты не получили распространения. В зарубежных клеевых составах в качестве основного липкогенного агента также используется преимущественно низкомолекулярный ПИБ с добавлением различных модифицирующих агентов для регулирования вязкости, адгезии к подложке, липкости (натуральные и синтетические каучуки, полипропилен, полиэтилен высокого и низкого давления, силикагель, органический бентонит и т.п.) [15-20].

К настоящему времени производство клея «Липофикс» затруднено изменившейся конъюнктурой российского рынка: цена высокомолекулярного ПИБ и НМПЭ выросла в несколько раз, а октол в России больше не производится. В связи с этим, актуальной является задача разработки модифицированного состава энтомологического клея на доступном и недорогом отечественном сырье, не уступающего по качеству «Липофиксу» и импортным аналогам.

\section{Результаты и их обсуждение}

В рамках поставленной задачи была разработана новая рецептура энтомологического клея, отличающаяся от вышеприведенной тем, что из состава был исключен дефицитный октол, а часть дорогостоящего высокомолекулярного ПИБ заменили более дешевым и доступным бутилкаучуком.
Кроме того, для повышения показателя липкости дополнительно использовали небольшие добавки канифоли. Были определены оптимальные соотношения компонентов, которые могут варьироваться в следующих пределах, \% мас.:

$$
\begin{aligned}
\text { - ПИБ } & 8.0-15.0 \\
- \text { бутилкаучук (БК) } & 4.0-7.0 \\
\text { - низкомолекулярный } & 35.0-50.0 \\
\text { полиэтилен (НМПЭ) } & 35.0-50.0 \\
\text { - масло } & 0.0-5.0 \\
\text { - канифоль сосновая } &
\end{aligned}
$$

Бутилкаучук является более доступным полимером на рынке и его стоимость практически в 2 раза ниже, чем у ПИБ. Добавление БК в количестве 4.0-7.0\% мас. позволяет существенно снизить себестоимость энтомологической композиции при сохранении хорошей биосовместимости, необходимой вязкости и технологичности получения и нанесения на основу, стабильности клеящих свойств во времени, высокого предела текучести (необходимого для предотвращения стекания клея с вертикальной поверхности).

В табл. приведены свойства энтомологических клеевых композиций, полученные при раз-

\begin{tabular}{|c|c|c|c|c|}
\hline \multicolumn{2}{|c|}{ Состав клеевой композиции } & \multicolumn{2}{|c|}{ Липкость, кгс/см² } & \multirow{2}{*}{ Предел текучести, ${ }^{\circ} \mathrm{C}$} \\
\hline Наименование компонента & Количество, \% мас. & 1-й день & 30-й день & \\
\hline \multicolumn{5}{|l|}{ Липофикс [2]: } \\
\hline НМПЭ-2 & 40.0 & \multirow{4}{*}{0.65} & \multirow{4}{*}{0.65} & \multirow{4}{*}{46} \\
\hline ПИБ-30 & 15.0 & & & \\
\hline Октол-600 & 20.0 & & & \\
\hline Масло И-20А & 25.0 & & & \\
\hline НМПЭ-2 & 40.0 & \multirow{4}{*}{0.70} & \multirow{4}{*}{0.70} & \multirow{4}{*}{53} \\
\hline ПИБ-30 & 15.0 & & & \\
\hline БК-1674H & 7.0 & & & \\
\hline Масло И-20А & 38.0 & & & \\
\hline НМПЭ & 40.0 & \multirow{5}{*}{0.83} & \multirow{5}{*}{0.82} & \multirow{5}{*}{56} \\
\hline ПИБ & 15.0 & & & \\
\hline БК & 7.0 & & & \\
\hline Масло И-20А & 33.0 & & & \\
\hline Канифоль & 5.0 & & & \\
\hline НМПЭ & 40.0 & \multirow{5}{*}{0.81} & \multirow{5}{*}{0.80} & \multirow{5}{*}{52} \\
\hline ПИБ & 15.0 & & & \\
\hline БК & 4.0 & & & \\
\hline Масло И-20A & 36.0 & & & \\
\hline Канифоль & 5.0 & & & \\
\hline НМПЭ & 40.0 & \multirow{5}{*}{0.79} & \multirow{5}{*}{0.79} & \multirow{5}{*}{51} \\
\hline ПИБ & 15.0 & & & \\
\hline БК & 4.0 & & & \\
\hline Масло И-20А & 39.0 & & & \\
\hline Канифоль & 1.0 & & & \\
\hline
\end{tabular}
личном соотношении компонентов. Оценивались предел текучести и показатели липкости в первый день и через 30 дней после нанесения на основу.

Таблица

Липкость и текучесть энтомологических клеевых композиций 
Как видно из табл., исключение из композиции октола и частичная замена дорогостоящего высокомолекулярного ПИБ на более дешевый бутилкаучук не только не привело к ухудшению свойств энтомологического клея по сравнению с «Липофиксом», но даже позволило повысить показатели липкости и предела текучести. Из полученных экспериментальных данных очевидно, что увеличение содержания БК и канифоли в составе композиции повышает показатели липкости и предела текучести. Тем не менее, увеличение содержания бутилкаучука более 7\% оказалось нецелесообразным, так как привело к существенному повышению вязкости состава, а это затрудняет нанесение клея на поверхность ловушек и ухудшает качество клея.

Для производства энтомологического клея в качестве сырья могут быть использованы: полиизобутилен c молекулярной массой $15 \cdot 10^{3}-50 \cdot 10^{3}$ (ПИБ-20, ПИБ-30, ПИБ-50) или импортный ПИБ со средневязкостной молекулярной массой от 60000 до 90000 г/моль; кондиционный или некондиционный бутилкаучук БК-1050, БК-1645, БК-1675, БК2045, БК-2055 марок А, Б, В; низкомолекулярный полиэтилен - побочный продукт производства полиэтилена высокого давления (НМПЭ-1, НМПЭ-2); минеральные масла (трансформаторное или индустриальное).

\section{Экспериментальная часть}

Для получения энтомологической клеевой композиции ПИБ-30 по ТУ 38.303-02-99-2011, БК1675Н по ТУ 2294-021-48158319-2012, НМПЭ-2 по ТУ 2211-091-05766563-2012, индустриальное масло И-20А по ГОСТ 20799.

Липкость (адгезию) определяли на разрывной машине РМИ-5 по ГОСТ 7762 при $20 \pm 2^{\circ} \mathrm{C}$ по усилию отрыва одного стального диска диаметром 24 мм от такого же другого под действием нагрузки с толщиной клеевого слоя 1 мм между дисками. Предел текучести характеризовался температурой начала стекания клеевой композиции толщиной $\sim 1$ мм с вертикально расположенной стеклянной подложки.

Приготовление клеевой композиции. В аппарат с мешалкой загружали расчетное количество масла, нагревали до $80-120^{\circ} \mathrm{C}$ и при постоянном перемешивании вводили НМПЭ. После полного растворения НМПЭ добавляли к смеси ПИБ и БК. В последнюю очередь загружали канифоль. Перемешивание прекращали после получения однородной, прозрачной, вязкой массы.

\section{Выводы}

Таким образом, разработан модифицированный состав энтомологической клеевой композиции на основе доступного и недорого сырья. Полученные клеевые композиции являются прозрачными, нетоксичными, имеют высокие эксплуатационные характеристики, легко наносятся на подложку и сохраняют липкость в течение длительного времени.

\section{ЛИТЕРАТУРА}

1. Вахитов В. А., Амирханов Д. В., Сангалов Ю. А. Новые средства и методы защиты растений. Сб. тр. БНЦ УрО РАН, Уфа: 1992. 154 с.

2. Сангалов Ю. А., Одиноков В. Н., Толстиков Г. А. Энтомологический клей «Липофикс» //А.c. 1383530. СССР. 1990.

3. Сангалов Ю. А., Романко Т. В., Мусин М. А. Энтомологические полимерные клеи как новые жидкофазные материалы // Башк. хим. журнал. 1996. Т. 3. №4. С. 17-22.

4. Сангалов Ю. А., Ильясова А. И., Лихоед В. А., Антонова Н. Е. Энтомологическая клеевая композиция // Патент 2179391. RU. 2002.

5. Лакеев С. Н., Сангалов Ю. А. Энтомологическая клеевая композиция // Патент 2236129. RU. 2004.

6. Сангалов Ю. А., Нелькенбаум Ю. Я., Одиноков В. Н., Толстиков Г.А., Романко Т. В., Понеделькина Ю. А., Никитин В. С., Ишмуратов Г. Ю. Энтомологический клей // A. c. 1701221. SU. 1991.

7. Нелькенбаум Ю. Я., Сангалов Ю. А., Романко Т. В., Понеделькина Ю. А. Энтомологический клей и способ его получения // Патент 2051162. RU. 1995.

8. Сангалов Ю. А., Кацюцевич Е. В., Ильясова А. И., Мусин М. А. Способ получения структурированной фенольной смолы из отходов производства фенола и ацетона кумольным методом // Патент 2081103. RU. 1997.

9. Сангалов Ю. А, Мусин М. А., Волкова Ю. Н. Клеевая композиция // Патент 2123020. RU. 1998.

10. Сангалов Ю. А., Джемилев У. М., Казаккулов Р. Г., Мусин М. А., Трифонов П. М. Способ защиты лесных насаждений от непарного шелкопряда // Патент 2129363. RU. 1999.

11. Сангалов Ю. А., Турьянов Р. А., Ильясова А. И., Мифтахов А. А., Науширванов Р. Р., Латыпов Ф. Ш. Энтомологический клеевой состав для защиты лесных насаждений // Патент 2158507. RU. 2000.

12. Сангалов Ю. А., Ильясова А. И., Антонова Н. Е., Лиходед В. А., Турьянов Р. А., Науширванов Р. Р., Латыпов Ф. Ш., Лиходед Т. А. Композиция для защиты лесных и культурных растений от насекомых-вредителей // Патент 2165145. RU. 2001.

13. Мануков Э. Н., Болотникова В. В., Шляшинский Р. Г., Войтеховская Г. И. Клеевая композиция для отлова бабочек зимней пяденицы // А. с. 1381149. SU. 1988.

14. Кяняусите Ю. М. Липкая масса для ловли насекомых // Патент 2028050. RU. 1995.

15. Takashima Ts. Adhesive for capturing small creature // Патент 4969102. JP. 2012.

16. Takashima Ts., Goshi Y. Adhesive composition for capturing small creature // Патент 4791821. JP. 2012.

17. Ida R., Goshi Y., Sato K. Adhesive composition for capturing small creature // Патент 2009203446. JP. 2009.

18. Nakatani H., Morimoto T. Sticky composition for trapping small living things and tool for trapping small living things // Патент 4146568. JP. 2008.

19. Matsubara S., Goushi Y. Improved adhesive composition for capturing small life // Патент H0256321. JP. 1990.

20. Shiraki Y., Kurashige Y. Pressure-sensitive adhesive composition // Патент H0554862. JP. 1993. 


\title{
DEVELOPMENT OF THE MODIFIED COMPOSITION
} OF ENTOMOLOGICAL ADHESIVES

\author{
(C) S. N. Lakeev ${ }^{1}$, I. Yu. Ponedelkina ${ }^{2}$, I. O. Maydanova ${ }^{3}$ \\ ${ }^{1}$ Ufa State Petroleum Technological University \\ 1 Kosmonavtov Street, 450062 Ufa, Republic of Bashkortostan, Russia. \\ ${ }^{2}$ Institute of Petrochemistry and Catalysis, RAS \\ 71 Oktyabrya Avenue, 450075 Ufa, Republic of Bashkortostan, Russia. \\ ${ }^{3}$ Innovation Center "Chemteq" \\ 43/1-29 Gagarin Street, 450105 Ufa, Republic of Bashkortostan, Russia.
}

Phone: +7 (347) 2948853.
*Email: lakeevsn@gmail.com

Entomological glue compositions are used in glue traps to catch harmful insects. Entomological compositions are multicomponent and contain sticking agents (natural or synthetic low molecular weight polymers), structure-forming additives (natural waxes, low molecular weight polyethylene, etc.) that regulate the mobility of the polymer component, as well as auxiliary substances and diluents for viscosity control. A modified composition of entomological glue is developed on the basis of available domestic raw materials with improved characteristics of tackiness and yield strength and reduced cost. As sticking agents in the composition, polyisobutylene having a molecular weight of $15 \cdot 10^{3}-50 \cdot 10^{3}$ in an amount of 8.0 to $15 \%$ by weight, butyl rubber in an amount of 4.0 to $7.0 \%$ by weight, and additionally pine rosin in an amount of up to $5 \%$ by weight were used. The composition also includes an industrial oil as a diluent and a low molecular weight polyethylene. Butyl rubber is a more affordable polymer on the market and its cost is almost 2 times lower than that of polyisobutylene. Addition of butyl rubber allows the authors to reduce the cost of entomological composition and maintain its biocompatibility, necessary viscosity and manufacturability of production and application to substrate, stability of adhesive properties in time, high yield strength (necessary to prevent glue from flowing from the vertical surface). In order to catch large insects, stickiness can be increased by addition of small amount of rosin. The resulting adhesive compositions are transparent, non-toxic, have high performance characteristics; they are easily applied to substrate and keep stickiness for a long time.

Keywords: entomological glue, polyisobutylene, butyl rubber, low molecular weight polyethylene, pine rosin.

Published in Russian. Do not hesitate to contact us at bulletin_bsu@mail.ru if you need translation of the article.

\section{REFERENCES}

1. Vakhitov V. A., Amirkhanov D. V., Sangalov Yu. A. Novye sredstva i metody zashchity rastenii [New means and methods of plant protection]. Sb. tr. BNTs UrO RAN, Ufa: 1992.

2. Sangalov Yu. A., Odinokov V. N., Tolstikov G. A.A.s. 1383530. SSSR. 1990.

3. Sangalov Yu. A., Romanko T. V., Musin M. A. Bashk. khim. zhurnal. 1996. Vol. 3. No. 4. Pp. 17-22.

4. Sangalov Yu. A., Il'yasova A. I., Likhoed V. A., Antonova N. E. Patent 2179391. RU. 2002.

5. Lakeev S. N., Sangalov Yu. A. Patent 2236129. RU. 2004.

6. Sangalov Yu. A., Nel'kenbaum Yu. Ya., Odinokov V. N., Tolstikov G.A., Romanko T. V., Ponedel'kina Yu. A., Nikitin V. S., Ishmuratov G. Yu. A. s. 1701221. SU. 1991.

7. Nel'kenbaum Yu. Ya., Sangalov Yu. A., Romanko T. V., Ponedel'kina Yu. A. Patent 2051162. RU. 1995.

8. Sangalov Yu. A., Katsyutsevich E. V., Il'yasova A. I., Musin M. A. Patent 2081103. RU. 1997.

9. Sangalov Yu. A, Musin M. A., Volkova Yu. N. Patent 2123020. RU. 1998.

10. Sangalov Yu. A., Dzhemilev U. M., Kazakkulov R. G., Musin M. A., Trifonov P. M. Patent 2129363. RU. 1999.

11. Sangalov Yu. A., Tur'yanov R. A., Il'yasova A. I., Miftakhov A. A., Naushirvanov R. R., Latypov F. Sh. Patent 2158507. RU. 2000.

12. Sangalov Yu. A., Il'yasova A. I., Antonova N. E., Likhoded V. A., Tur'yanov R. A., Naushirvanov R. R., Latypov F. Sh., Likhoded T. A. Patent 2165145. RU. 2001.

13. Manukov E. N., Bolotnikova V. V., Shlyashinskii R. G. A. s. 1381149. SU. 1988

14. Kyanyausite Yu. M. Patent 2028050. RU. 1995.

15. Takashima Ts. Patent 4969102. JP. 2012.

16. Takashima Ts., Goshi Y. Patent 4791821. JP. 2012.

17. Ida R., Goshi Y., Sato K. Patent 2009203446. JP. 2009.

18. Nakatani H., Morimoto T. Patent 4146568. JP. 2008.

19. Matsubara S., Goushi Y. Patent H0256321. JP. 1990.

20. Shiraki Y., Kurashige Y. Patent H0554862. JP. 1993. 